energy expenditure. 'Exercise' refers to planned, structured and repetitive movement to improve or maintain one or more components of physical fitness (Chodzko-Zajko et al, 2009). So a person may take little exercise but be physically active with low levels of sedentary behaviour, whereas another might do structured exercises but be habitually inactive and spend long periods sedentary. Thus, the end points of some of the reviewed trials and the methods used to measure those end points require more critical discussion. For example, the authors acknowledge that aerobic exercise tolerance may not reflect aerobic fitness - but neither of those necessarily translates into improved habitual physical activity. The authors acknowledge the challenge of achieving current physical activity guidelines, but do not mention potential end points at the lower end of the physical activity continuum - for example, breaking up sedentary behaviour with light activity - which may be critical in cancer survivors, given recent recognition of the adverse health consequences of high levels of sedentary behaviour in cancer populations (Lynch et al, 2013).

We would also like to draw particular attention to differences between the reviewed studies in the methods used to measure physical activity end points, such as self-report measures, heart rate monitors and accelerometers. Two studies (Pinto et al, 2005, 2013) included in the analysis showed that selfreport measures did not correspond with objectively measured physical activity, which we also found in both an observational (Broderick et al, 2013b) and an intervention study (Broderick et al, 2013a). Unless sedentary behaviour and all physical activity, including exercise, are accurately, consistently and objectively measured across studies, using, for example, accelerometers, we think it will be impossible to answer the 'million dollar' question of how best to improve habitual physical activity and adherence to guidelines for health benefits in cancer patients and survivors.
CONFLICT OF INTEREST

The authors declare no conflict of interest.

\section{REFERENCES}

Bourke L, Homer KE, Thaha MA, Steed L, Roasario DJ, Robb KA, Saxton JM, Taylor SJC (2014) Interventions to improve exercise behaviour in sedentary people living with and beyond cancer: a systematic review. Br J Cancer 110: 831-841.

Broderick JM, Guinan E, Kennedy MJ, Hollywood D, Courneya KS, Culos-Reed SN, Bennett K, OD DM, Hussey J (2013a) Feasibility and efficacy of a supervised exercise intervention in de-conditioned cancer survivors during the early survivorship phase: the PEACH trial. J Cancer Surviv 7(4): 551-562.

Broderick JM, Hussey J, Kennedy MJ, O’Donnell DM (2013b) Testing the 'teachable moment' premise: does physical activity increase in the early survivorship phase? Support Care Cancer 22(4): 989-997.

Chodzko-Zajko WJ, Proctor DN, Fiatarone Singh MA (2009) American College of Sports Medicine position stand. Exercise and physical activity for older adults. Med Sci Sports Exerc 41: 1510-1530.

Lynch BM, Dunstan DW, Vallance JK, Owen N (2013) Don't take cancer sitting down: a new survivorship research agenda. Cancer 119(11): 1928-1935.

Pinto BM, Frierson GM, Rabin C, Trunzo JJ, Marcus BH (2005) Home-based physical activity intervention for breast cancer patients. J Clin Oncol 23(15): $3577-3587$

Pinto BM, Papandonatos GD, Goldstein MG, Marcus BH, Farrell N (2013) Homebased physical activity intervention for colorectal cancer survivors. Psychooncology 22(1): 54-64.

*Correspondence: Dr JM Broderick; E-mail: julie.broderick@tcd.ie

Published online 8 May 2014

(C) 2014 Cancer Research UK. All rights reserved 0007 - 0920/14

http://creativecommons.org/licenses/by-nc-sa/3.0/

\title{
Response to comment on 'Interventions to improve exercise behaviour in sedentary people living with and beyond cancer: a systematic review'
}

\author{
L Bourke $^{*}{ }^{1}$, D J Rosario ${ }^{2}$, L Steed ${ }^{1}$ and S J C Taylor ${ }^{1}$ \\ ${ }^{1}$ Primary Care and Public Health, Blizard Institute, Queen Mary University of London, London, UK and ${ }^{2}$ Academic Urology Unit, Department of \\ Oncology, E Floor, Royal Hallamshire Hospital, University of Sheffield, Glossop Road, Sheffield, UK
}

Sir,

We thank Broderick et al (2014) for their interest in our manuscript. We agree there seems to be uncertainty in the terminology around exercise interventions, which has not been helped by the implication of a distinction between the terms 'physical activity' and 'exercise' in some publications (Chodzko-Zajko et al, 2009). A more constructive approach would appear to be that taken by Winter and Fowler, (2009) in defining and quantifying exercise according to the Systeme International d'Unites. As stated in the review, this is the approach we chose to follow, for several reasons:

1. An important aspect of a systematic review is to summarise the current evidence base with a view to identifying prospective research priorities or furthering practice. In this context, making a distinction between physical activity and exercise is unhelpful, particularly in evaluating clinical effectiveness. As in other clinical trials, most notably drug studies, objective documentation of the amount of the intervention that is delivered is imperative to identify dose-response curves and adverse effects. The review criteria were set to include only studies reporting such objective metrics (i.e., frequency, intensity and duration) so as to facilitate reproducibility of the intervention. Any systematic review of cancer therapies will clearly identify the target population and objectively define the intervention; exercise is no different, if we are to take its use as a therapeutic intervention seriously.

2. The term 'sedentary behaviour' is open to uncertainty, as considerable exercise may be taking place in a sedentary (i.e., seated) position-for example, rowing or cycling. We agree this needs defining, but to do so by subdividing exercise into different terms, seems counterproductive. Sedentary behaviour could be defined as anyone not achieving the recommendation to take $150 \mathrm{~min}$ per week of moderate-intensity aerobic exercise (Rock et al, 2012). However, in clinical trials involving cancer cohorts, this has frequently been defined as $<90$, or even $<60$ min per week (Pinto et al, 2005; Daley et al 2007; Cadmus et al, 2009; Bourke et al, 2014). The rationale being that there should be some scope to induce a clinically meaningful benefit from participation in the intervention. If there is not, why do we need to intervene? Nevertheless, as we concluded in the review, most individuals living with or beyond cancer would currently find current guideline targets unachievable, certainly with current published interventions. More research or a revision of the one size fits all approach is warranted. We conclude in the review that a 'dose response' might be more appropriate. This would include the suggested 'potential end-points at the lower end of the physical activity continuum.' Such recommendations might require elucidation by further data collection or an individual patient data meta-analysis for any given health outcome.

3. The tendency of epidemiological studies to imply a distinction between exercise and physical activity reflects imprecision of measurement rather than any fundamental difference. Subjective metrics of exercise behaviour, for example, metabolic equivalents derived from questionnaires (Ainsworth et al, 2011), are often used in these reports and we agree that objective measurement of exercise behaviour are preferable in clinical trials. Dedicated accelerometers seem an overly expensive option. Less expensive alternatives such as smartphone applications or simple heart rate monitors would be welcome where the technology is available, affordable and contextually appropriate. For individuals on prescribed medication (e.g., $\beta$ blockers) that impact the cardiovascular response to physical exertion, reliable measurement of dose-response remains a challenge.

Finally, as Jan Swammerdam's 17th century experiments demonstrated rather elegantly (Needham, 1971; Winter and Fowler, 2009), skeletal muscles neither 'contract' (i.e., reduce in volume) nor expand significantly during exercise. Furthermore, movement is neither essential nor necessary (as in isometric activity) for exercise to be taking place. What is fundamental to exercise, in the context being discussed, is skeletal muscular activity exerting force and generating a metabolic response i.e. physical activity by a different name.

We look forward to reaching consensus on the role of defined exercise interventions in the treatment of a number of cancers and agree with Broderick et al that consensus on terminology is an essential first step. We would encourage all practitioners in this area to follow the excellent recommendations of Winter and Fowler, which perpetuate reproducibility rather than confusion.

\section{REFERENCES}

Ainsworth BE, Haskell WL, Herrmann SD, Meckes N, Bassett Jr DR, Tudor-Locke C, Greer JL, Vezina J, Whitt-Glover MC, Leon AS (2011) Compendium of Physical Activities: A Second Update of Codes and MET Values. Med Sci Sports Exerc 43(8): 1575-1581.

Bourke L, Gilbert S, Hooper R, Steed LA, Joshi M, Catto JW, Saxton JM, Rosario DJ (2014) Lifestyle changes for improving disease specific quality of life in men on androgen deprivation therapy for advanced prostate cancer. Eur Urol 65(5): 865-872. 
Broderick JM, Hussey J, O'Donnell DM (2014) Comment on 'Interventions to improve exercise behaviour in sedentary people living with and beyond cancer: a systematic review'. Br J Cancer 111(12): 2377-2378.

Cadmus LA, Salovey P, Yu H, Chung G, Kasl S, Irwin ML (2009) Exercise and quality of life during and after treatment for breast cancer: results of two randomized controlled trials. Psychooncology 18(4): 343-352.

Chodzko-Zajko WJ, Proctor DN, Fiatarone Singh MA, Minson CT, Nigg CR, Salem GJ, Skinner JS (2009) American College of Sports Medicine position stand. Exercise and physical activity for older adults. Med Sci Sports Exerc 41(7): 1510-1530.

Daley AJ, Crank H, Saxton JM, Mutrie N, Coleman R, Roalfe A (2007) Randomized trial of exercise therapy in women treated for breast cancer. J Clin Oncol 25(13): 1713-1721.
Needham DM. Machina Carnis: The Biochemistry of Muscular Contraction in its Historical Development. CUP: Cambridge (1971).

Pinto BM, Frierson GM, Rabin C, Trunzo JJ, Marcus BH (2005) Home-based physical activity intervention for breast cancer patients. J Clin Oncol 23(15): 3577-3587.

Rock CL, Doyle C, Demark-Wahnefried W, Meyerhardt J, Courneya KS, Schwartz AL, Bandera EV, Hamilton KK, Grant B, McCullough M, Byers T, Gansler T (2012) Nutrition and physical activity guidelines for cancer survivors. CA Cancer J Clin 62(4): 243-274.

Winter EM, Fowler N (2009) Exercise defined and quantified according to the Systeme International d'Unites. J Sports Sci 27(5): 447-460.

*Correspondence: Dr L Bourke; E-mail: I.bourke@qmul.ac.uk

Published online 27 May 2014

(C) 2014 Cancer Research UK. All rights reserved 0007-0920/14

http://creativecommons.org/licenses/by-nc-sa/3.0/

\title{
Comment on 'KRAS-mutated plasma DNA as predictor of outcome from irinotecan monotherapy in metastatic colorectal cancer'
}

\author{
D Tougeron *,1, P Laurent-Puig ${ }^{2}$ and A Zaanan ${ }^{2,3}$
}

${ }^{1}$ Department of Gastroenterology, Poitiers University Hospital, Poitiers, France; ${ }^{2}$ UMR-S775, INSERM, Paris, France and ${ }^{3}$ Department of Gastroenterology and Digestive Oncology, European Georges Pompidou University Hospital, AP-HP, Paris, France

Sir,

We read with great interest the article 'KRAS-mutated plasma DNA as predictor of outcome from irinotecan monotherapy in metastatic colorectal cancer' published by (Spindler et al, 2013) in the December 2013 issue of the British Journal of Cancer. It is now well established that only patients with wild-type KRAS metastatic colorectal cancer benefit from treatment with an anti-epidermal growth factor receptor (EGFR) monoclonal antibody and that patients with KRAS mutant metastatic colorectal cancer do not (Karapetis et al, 2008; Douillard et al, 2010). Up until now, DNA from archival tumour tissue is used to determine KRAS mutations in clinical practice. Increased recent data indicate that circulating tumour DNA in plasma, could be a new way to analyse the somatic mutation in tumours and could be a potential biomarker to ensure optimal treatment (Murtaza et al, 2013). Spindler et al (2013) aimed to investigate the clinical implication of KRAS and BRAF mutations in both archival tumour tissue and plasma cell-free DNA in 211 metastatic colorectal cancer patients treated with second-line irinotecan monotherapy. Authors observed that plasma KRAS mutations, but not tumour KRAS mutations, were associated with worse disease control rate, progression-free survival and overall survival. However, contrary to what is mentioned in the title, the predictive impact of the plasma KRAS and BRAF mutations for the irinotecan response treatment cannot be evaluated in this study because there is no control arm (patients receiving other therapies or no therapy).

In this study, KRAS mutations have been detected less frequently in plasma $(31 \%)$ as compared in tumour (45\%) (16 patients with a wild-type KRAS plasma had a mutation in the tumour). Tumour KRAS mutations were analysed in formalin-fixed paraffin-embedded tissue obtained at diagnosis, whereas plasma KRAS mutations were analysed in pretreatment blood samples before the beginning of second-line irinotecan monotherapy. The description of patients receiving an anti-EGFR in first-line therapy would be an interesting information, as acquired KRAS mutations can be induced by these therapies (Misale et al, 2012). The presence of a minority subclone harbouring KRAS mutations within tumours might explain the secondary resistance to anti-EGFR therapy (Tougeron et al, 2013) and the emergence of plasma KRAS mutations (Diaz et al, 2012).

Furthermore, the discordance for the KRAS mutation detection rate between tumour and plasma could be explained by a lack of sensitivity for the plasma KRAS mutations detection or by the absence of circulating tumour DNA for some patients. The amplification refractory mutation system-quantitative PCR (ARMS-qPCR) methodology, used in this study, has a sensitivity around $0.1 \%$ (Fox et al, 1998; Nordgård et al, 2012). Some studies have suggested that ARMS has an insufficient sensitivity to detect low levels of KRAS mutation (Nordgård et al, 2012). Indeed, the level of circulating tumour DNA in plasma can be very low and may represent only a small fraction of the total circulating DNA $(<0.01 \%)$ (Diehl et al, 2008; Taly et al, 2013). Techniques with very high sensitivity for circulating tumour DNA detection have been recently developed (Taly et al, 2012), such as microdroplet technology, which can detect one mutant KRAS gene among 200000 wild-type KRAS genes in the plasma (Pekin et al, 2011). Thus, we think that the results of the study by Spindler et al (2013) should be interpreted with caution because the poor prognosis of patients with plasma KRAS mutation could only reflect the poor prognosis of patients with a high level of circulating tumour DNA, as suggested by some others studies (Lefebure et al, 2010; Spindler et al, 2012). In contrast, the better prognosis could only reflect the low level of circulating tumour DNA that is not detectable by the ARMS assay for the KRAS mutation testing.

In conclusion, this promising work published by Spindler et al (2013) highlights the impact of circulating tumour DNA on the treatment response of metastatic colorectal cancer. Moreover, it strengthens the need for harmonising detection methods for KRAS mutations and to develop highly sensitive techniques for plasma testing. Thus, correlation of KRAS mutation in primary tumours, metastases and plasma during metastatic colorectal therapies still needs to be studied.

\section{CONFLICT OF INTEREST}

The authors declare no conflict of interest.

\section{REFERENCES}

Diaz Jr LA, Williams RT, Wu J, Kinde I, Hecht JR, Berlin J, Allen B, Bozic I, Reiter JG, Nowak MA, Kinzler KW, Oliner KS, Vogelstein B (2012) The molecular evolution of acquired resistance to targeted EGFR blockade in colorectal cancers. Nature 486: 537-540.

Diehl F, Schmidt K, Choti MA, Romans K, Goodman S, Li M, Thornton K, Agrawal N, Sokoll L, Szabo SA, Kinzler KW, Vogelstein B, Diaz LA Jr (2008) Circulating mutant DNA to assess tumor dynamics. Nat Med 14: 985-990.

Douillard JY, Siena S, Cassidy J, Tabernero J, Burkes R, Barugel M, Humblet Y, Bodoky G, Cunningham D, Jassem J, Rivera F, Kocákova I, Ruff P, Błasińska-Morawiec M, Smakal M, Canon JL, Rother M, Oliner KS, Wolf M, Gansert J (2010) Randomized, phase III trial of panitumumab with infusional fluorouracil, leucovorin, and oxaliplatin (FOLFOX4) versus FOLFOX4 alone as first-line treatment in patients with previously untreated metastatic colorectal cancer: the PRIME study. J Clin Oncol 28: 4697-4705.

Fox JC, England J, White P, Ellison G, Callaghan K, Charlesworth NR, Hehir J, McCarthy TL, Smith-Ravin J, Talbot IC, Snary D, Northover JM, Newton CR, Little S (1998) The detection of K-ras mutations in colorectal cancer using the amplification-refractory mutation system. Br J Cancer 77: 1267-1274.

Karapetis CS, Khambata-Ford S, Jonker DJ, O'Callaghan CJ, Tu D, Tebbutt NC, Simes RJ, Chalchal H, Shapiro JD, Robitaille S, Price TJ, Shepherd L, Au HJ, Langer C, Moore MJ, Zalcberg JR (2008) K-ras mutations and benefit from cetuximab in advanced colorectal cancer. $N$ Engl J Med 359: 1757-1765.

Lefebure B, Charbonnier F, Di Fiore F, Tuech JJ, Le Pessot F, Michot F, Michel P, Frebourg T (2010) Prognostic value of circulating mutant DNA in unresectable metastatic colorectal cancer. Ann Surg 251: 275-280.

Misale S, Yaeger R, Hobor S, Scala E, Janakiraman M, Liska D, Valtorta E, Schiavo R, Buscarino M, Siravegna G, Bencardino K, Cercek A, Chen CT, Veronese S, Zanon C, Sartore-Bianchi A, Gambacorta M, Gallicchio M, Vakiani E, Boscaro V, Medico E, Weiser M, Siena S, Di Nicolantonio F, Solit D, Bardelli A (2012) Emergence of KRAS mutations and acquired resistance to anti-EGFR therapy in colorectal cancer. Nature 486: 532-536.

Murtaza M, Dawson SJ, Tsui DW, Gale D, Forshew T, Piskorz AM, Parkinson C, Chin SF, Kingsbury Z, Wong AS, Marass F, Humphray S, Hadfield J, Bentley D, Chin TM, Brenton JD, Caldas C, Rosenfeld N (2013) Non-invasive analysis of acquired resistance to cancer therapy by sequencing of plasma DNA. Nature 497: 108-112.

Nordgård O, Oltedal S, Janssen EA, Gilje B, Kørner H, Tjensvoll K, Smaaland R (2012) Comparison of a PNA clamp PCR and an ARMS/Scorpion PCR assay for the detection of K-ras mutations. Diagn Mol Pathol 21: 9-13. Pekin D, Skhiri Y, Baret JC, Le Corre D, Mazutis L, Salem CB, Millot F, El Harrak A, Hutchison JB, Larson JW, Link DR, Laurent-Puig P, Griffiths AD, Taly V (2011) Quantitative and sensitive detection of rare mutations using droplet-based microfluidics. Lab Chip 11: 2156-2166. 